\title{
Monitoring and manipulation of New Zealand flower thrips (Thrips obscuratus) in summerfruit orchards
}

\author{
M.E. Stanbury ${ }^{1}$, E. de Vries ${ }^{1}$, A.M. El-Sayed ${ }^{1}$, F. Chinellato ${ }^{3}$, K. M. Colhoun ${ }^{2}$, B. Attfield ${ }^{2}$ and \\ D.M. Suckling ${ }^{1}$
}
${ }^{1}$ The New Zealand Institute for Plant E Food Research Limited, Private Bag 4704, Christchurch 8140, New Zealand
${ }^{2}$ The New Zealand Institute for Plant E Food Research Limited, 990 Earnscleugh Road, RD 1, Alexandra 9391, New Zealand
${ }^{3}$ Universita' di Padova, DAFNAE-Entomologia, Agripolis - Viale dell'Universita 16, 35020 Legnaro PD, Italia Corresponding author: mailee.stanbury@plantandfood.co.nz

New Zealand flower thrips (NZFT) are a pest in New Zealand stone fruit orchards. In this study, NZFT density was manipulated in the field using a known kairomone. It was discovered that the addition of the kairomone to any given tree within an orchard increased NZFT density in direct proportion to the amount of kairomone used. It was also found that delta traps baited with kairomone must be within $1.5 \mathrm{~m}$ from each other before trap competition occurs, indicating a high density of traps is required for mass trapping. Daily monitoring of NZFT catch using self-reporting camera trap technology in a Clyde orchard revealed that despite large daily variation in NZFT catch, the population displayed a linear growth trend. This indicates that NZFT establishment in Central Otago cannot be explained by the sudden arrival of windborne adults as previously thought. These results indicate that it may be possible to manipulate NZFT density within an orchard in such a way that the majority of fruiting trees are 'protected' by 'trap trees' during harvest.

\section{Development of citrophilus mealybug (Pseudococcus calceolariae) on grape roots}

W.R.M. Sandanayaka, V.A. Davis and D. Cohen

New Zealand Institute for Plant E Food Research Limited, Private Bag 92-169, Auckland 1142, New Zealand Corresponding author: Manoharie.Sandanayaka@plantandfood.co.nz

Pseudococcus calceolariae (Hemiptera: Pseudococcidae) is a vector of Grapevine leafroll-associated virus 3 (GLRaV-3), the most destructive virus disease affecting New Zealand grapevines. Previous studies suggest that $P$. calceolariae can survive on remnant vine roots for at least 12 months and these mealybugs could account for the spread of the disease in replanted vineyards. A laboratory assay test was developed to observe the growth of $P$. calceolariae on grape rootstock 3309. Clean root pieces were left on moist filter paper in Petri dishes for a week to encourage new growth before P. calceolariae eggs $(n=15)$ were inoculated and held at $23^{\circ} \mathrm{C}$. Recordings were made every 3-4 days of the survival and development from first instar until males emerged as adults and females started oviposition. About 50\% mortality was recorded during first and second instars and ca 30\% developed into adult stages. The development periods from first instar to adult males and females were $44.1 \pm 1(n=16)$ and $45.4 \pm 1(n=22)$ respectively. This methodology is being developed to assess the relative resistance of grapevine rootstocks, effects of contact insecticides and to understand GLRaV-3 transmission from roots. 